\title{
Transforming Japan's Space Policy-making
}

\author{
Kazuto Suzuki \\ Graduate School of Humanities and Social Sciences \\ University of Tsukuba \\ Tsukuba, Japan \\ suzuki@social.tsukuba.ac.jp \\ Tel/Fax: +81-29-853-6209
}

\begin{abstract}
The objective of Japanese space policy, since its beginning, was to "catch-up" with advanced spacefaring countries. However, this "catching up" strategy is now facing with a lot of difficulties, due to the downturn of economy and progress of Japanese technology. In these circumstances, Japanese space community realized the necessity for changing its national space strategy. In 2005, some Japanese powerful politicians issued a report on constructing national space strategy which demanded the government to establish new decision-making structure. These efforts are focusing the need for Japanese space to shift the focus of policy from technological development to application.
\end{abstract}

\section{Introduction}

Japanese space policy is now in a transition. By the time of publication of this article, a bill might have been submitted to the Diet for establishing the "Basic Law of Space Activities", submitted by members of the Diet ${ }^{1}$. This is the first time since the late-1960s that Japanese politicians took action for intervening space policy-making. This law not only aims for stimulating space activities in Japan, but for transforming the normative base of Japanese space policy-making from R\&D oriented policy to user-driven policy. Furthermore, it challenges the normative assumption of "exclusively peaceful purpose" clause in the Diet resolution in 1969. These aims and challenges are indeed a significant change from the past experience of Japanese space policy-making.

It is the task of this paper to explore why such a change happened in Japan. Why, in a sudden, politicians became interested in committing themselves in space policy? What made them changed their minds? How is this transformation accepted by traditionally dominating space actors such as JAXA? What would be the consequences if the Basic Law passed the Diet? And, after all, does this Basic Law transform Japanese space policy-making process? In answering these ques-

\footnotetext{
${ }^{1}$ Most of Japanese law is submitted by the government. Over $85 \%$ of the law passed the Diet is drafted by bureaucrats and submitted by the Minister of concerned issues. The number of law submitted by the members of Diet is gradually increasing, but it is still marginal to the government-sponsored law.
} 
tions, this paper discusses the context of Japanese space policy-making since 1960s, and recent changes of circumstances around space activities in Japan. It will then examine the proposed contents of the Basic Law and analyzes the aims and objectives of the Law. Through this analysis, this paper intends to provide possible scenarios of Japanese space policy development in near future.

\section{Japanese Space Policy-making in Context}

It is often said that Japanese space policy is incomprehensible. Perhaps, one of the reasons of this incomprehensibility is that Japanese space policy does not share the same normative assumptions with other spacefaring states ${ }^{2}$. First of all, there was a very little political and strategic implication in space policy. It is largely due to the fact that Japan, with a pacifist Constitution, refrained from using space for security purposes. In 1969, the Diet has adopted a resolution called “Space Development for Exclusively Peaceful Purposes”, which limited any involvement of defense authority for investing in, owning of and operating space systems. In other words, all Japanese space programs were conducted under civilian authority in the name of research and development of new technology.

Because of this Diet resolution, the space activities were entirely isolated and folded into a category of Science and Technology policy. The strategic goal for Japanese space policy was, thus, set to "catch-up" with other advanced spacefaring countries such as the United States or Europe. For many politicians, space was a "necktie of advanced countries" ${ }^{3}$, which suggests that Japanese space policy was developed for national prestige of being a member of advanced industrialized countries' club.

This normative context is extremely important for understanding current transition of Japanese space policy-making. For a long time, most of space programs --- even application programs for communication, broadcasting, and meteorology --- were driven by technological excellence. In other words, robustness, reliability, and low cost were not the priority for Japanese space manufacturers. They were more interested in adapting new technologies and progressing in engineering know-how. Furthermore, because space policy was folded in science and technology policy, the focus on technology and R\&D was justified by politicians and financial authority for granting large sum of budget.

Secondly, given the technological focus of Japanese space policy, the major decision-makers were not politicians or ministers, but bureaucratic machinery. For a long time, Japanese space policy was dominated by Science and Technology Agency (STA) and Ministry of Education, Culture and Sports (MoE). Space Activities Commission (SAC) under Cabinet Office was

\footnotetext{
${ }^{2}$ For understanding the development of Japan's space policy logics, see Kazuto Suzuki, "Administrative Reforms and Policy Logics of Japanese Space Policy", Space Policy, vol.21 no.1, 2005: pp.11-19.

3 This expression was used by Shinya Matsuura in his book Kokusan Rocket ha Naze Ochirunoka (Why Japanese Launcher fails). Nikkei BP Publishers, 2004.
} 
acting as the inter-ministerial coordination framework, but because STA was in charge for providing secretariat services, most of decision-making at SAC was initiated and framed by STA. This engineer-bureaucrat oriented policy making framework did not change even when there was a large ministerial restructuring early in this century.

At the beginning of 2001, STA and MoE merged into a very big ministry (Ministry of Education, Culture, Sports, Science and Technology: MEXT) in charge of two principle space agencies, National Space Development Agency (NASDA) and Institute of Space and Aeronautical Science (ISAS). The two agencies were eventually merged to create a single agency for aerospace (Japanese Aerospace Exploration Agency: JAXA) together with National Aerospace Laboratory (NAL). At the same time, the inter-ministerial decision-making body for space, Space Activities Committee (SAC), was reduced its responsibility only to the supervision of the space activities within MEXT and JAXA. Instead, the Council of Science and Technology Policy (CSTP), of which the prime minister is the chairperson, was created to oversee national strategy for all areas of science and technology policy including space ${ }^{4}$.

However, this administrative reform has not changed the normative base of Japanese space policy-making. Still the bureaucratic machinery was in charge of the decision-making, and structure for strategic planning and political intervention did not emerge. Meanwhile, the old bureaucratic tradition based on the ex-STA engineers remained in this newly created larger ministries and inter-ministerial body such as CSTP which was busy dealing with variety of science and technological issues other than space.

Thirdly, relating to the first and the second points, the accord with United States in 1990 for opening government satellite procurement for public tender enhanced the normative assumption for Japan to focus on technological development. During the late 1980s, Reagan and Bush Sr. administrations strongly claimed that Japan was a country with unfair trade, threatening to invoke unilateral sanction against Japan by using Article 301 of the US Trade Act (so-called "super 301"). The US government criticised that Japanese government protected its industry through opaque public procurement protocols, regulations, and business customs, which made it difficult for the US industry to penetrate Japanese market. The US government threatened to impose punitive tariff on Japanese major export items such as automobile and super computer. At the end of the negotiation, Japanese government agreed to conclude an accord for opening the public procurement procedure of non-R\&D satellite for international bidders ${ }^{5}$. This agreement had a very damaging effect on Japanese satellite industry, since its competitiveness was much lower than that of US companies, and in

\footnotetext{
${ }^{4}$ For understanding the process of administrative reform and space policy in Japan, see Suzuki, op. cit.

${ }^{5}$ See Masahiko Sato, T. Kosuge, and P. van Fenema, "Legal Implications on Satellite Procurement and Trade Issues between Japan and the United States", Paper presented in Institute of International Space Law Conference (IISL-99-IISL.3.13), 1999.
} 
fact, almost all non-R\&D satellites were procured from US manufacturers since then ${ }^{6}$. However, Japanese companies kept calm over this agreement which may have devastating effect on their business, because most of satellite manufacturers in Japan were producers of super computers and electronic goods. It was also them who would have suffered if the US government had imposed sanctions. Putting it simply, they preferred supercomputer over satellites.

As a result of this agreement, NASDA had to focus on R\&D satellite which was the only allowed activity for the government to offer contracts to Japanese industry. The industry, on the other hand, was not extremely enthusiastic for improving its competitiveness, largely because they considered that the space business was not commercially profitable, and it was sufficient to receive R\&D contracts from NASDA for its survival. Furthermore, the rationale to keep their space business was to contribute Japanese technological development for strengthening the position of Japan in international arena, thus, there were little incentives for Japanese industry to take risks for commercialization of space or to reduce costs and improve its efficiency.

\section{Changing Economic and Administrative Circumstances}

Concerns over government's budget deficit and inefficiency of bureaucracy has been a subject of political discussion since mid-1990s. Due to the long-term recession, tax revenue continuously declined while inefficient bureaucratic expenditure was in a trend of increase. Since the beginning of 1990s, government bond issue has increased dramatically for stimulating stagnated economy. In 1994, the cumulated debts exceeded 200 trillion yen (about $\$ 1.81$ trillion), which is beyond the total of debt of third world countries. In 1998, it doubled to 427 trillion yen (about $\$ 3.81$ trillion), and currently in 2006, it is 827 trillion yen (about $\$ 7.51$ trillion) ${ }^{7}$. This explosive increase of public debt made Japanese government on the verge of bankruptcy. The government was forced to take action to reduce government spending and revitalise the economy. In 1996, Prime Minister Hashimoto initiated a project to rationalise ministerial structure and to reduce the number of civil servants. Hashimoto who had a keen awareness of the budgetary problem realised that it was time to shift towards "small and efficient government". This period also coincided with strong criticism against corruption, opaque decision-making process, and favouritism toward big business was mounting. Thus, for avoiding public criticism and decreasing government spending, the discussion for administrative reform began. The process of implementation of ministerial reform took more than five years because of a strong opposition from bureaucrats and their allied politicians. As a result of this reform, MoE merged with STA (which is now called Ministry of Education, Culture, Sports, Science and Technology or MEXT) and MITI became the Ministry of Economy, Trade and Industry (METI) by absorbing the some functions of the Economic Planning

\footnotetext{
${ }^{6}$ The only exception was the Multipurpose Transport Satellite 2 (MTSAT-2).

${ }^{7}$ Ministry of Finance, National Debt Report 2006 (Exchange rate \$1=¥110).
} 
Agency.

The merger of MoE and STA, the supervising ministries of NASDA and ISAS respectively, raised expectation in space policy community that this would end the long-standing division within the Japanese space policy and would induce a synergy effect. However, the consequence of this merger increased the confusion of the policy-making process. Because of the principle of exchanging personnel between two ministries, the head of space policy division of MEXT was designated as a seat of former education bureaucrat. The center of space policy-making in the MEXT was occupied by those who have experience in academic grant, exchange student affairs and elementary school education. Even before the merger, the head of the division was occupied by non-space expert, but at least the head had some background knowledge in the fields of science and technology. The administrative reform seemingly increased the efficiency, but in reality, it created confusion in space policy-making.

Speaking of the confusion of space policy-making, the administrative reform also influenced the position of the highest level of decision-making. SAC, once the central inter-ministry coordinating body and reporting directly to the Prime Minister, became much smaller organisation only responsible for the JAXA matters (though it deals with most of the space activity in Japan). Currently no inter-ministerial coordination for space activities exists. On the other hand, CSTP was created to coordinate S\&T policy independently from ministries. Although the CSTP is much higher organisation in bureaucratic hierarchy, it does not have the power to formulate budget line. It is only an advisory council for the Prime Minister. The SAC, on the other hand, still maintains the power to decide how much fund should be allocated to which programs. However, since SAC became only a committee under MEXT, the decision of SAC is no longer the final one as it should be channelled through MEXT for further negotiation with the Ministry of Treasury. The importance of SAC is diminished further because the chairman is no longer the Secretary of State for Science and Technology, but it is chaired by someone outside space community, who has less influence and knowledge about the space activities. The confusion in the decision-making process thus continues.

In addition to the confusion in decision-making process, there are severe financial constraints on Japanese space policy. Although the nominal space budget does maintain a flat line at 200 billion Yen (about $\$ 1.8$ billion) for the last few years, the real money which is spent on Japanese space programmes is seriously dropping. This lack of funding was not only due to the budgetary constraints, but also from the lower priority and political attention from the government. With the consecutive failures (ADEOS-2, Planet-B, and H-IIA with two IGS satellites) in early 2000s, Japanese government began to question whether the funding for space development was efficiently used to bring successful missions. The general trend of shrinking budget may not change for a while. 


\section{Shocks in Post-Cold War Period}

But most importantly, the post-Cold War period has brought new circumstances to Japanese space strategy. First of all, the changes of security environment have made it difficult for Japan to continue its pacifist policy. During the Cold War, there was a mutual interest between the governments of Japan and the United States. For the US, it was important to have Japan as a front line defense towards the Soviet and Communist threat to Pacific Ocean. For Japan, the alliance with the US was the core of its pacifist concept for not having any offensive military forces. Without US forces present in Japan, it would only be able to defend when the hostile action taken place in its territory and not be able to take any counter-measure in enemy's territory.

However, the situation in the post-Cold War period is somewhat different from the previous period. The threat of Communism has dramatically reduced, and the reasons for stationing US troops in Japan became also ambiguous. Although the US still maintained a need for stationing in Japan as a forward deployment base, it does no longer imperative to protect Japan in the name of alliance. Thus, the US government shifted its policy to "share more burdens" with Japanese government, in other words, Japan should contribute more for the actions of the United States for the security matters. The consequence of this was Japanese participation in War on Terror, particularly deployment of naval forces to support US-led operation in Afghanistan and ground troops in Iraq.

Through these operations, Japanese Self-Defense Force (SDF) realized the important technological gap for its own operations. Since SDF was restricted from developing and operating its own space capabilities, it had to rely on commercial satellite communication and commercial imagery services. Because in the past, SDF was not supposed to go beyond its borders, so there was no need for communication in long distance or collecting imagery of other countries other than its neighbours. Furthermore, through these operations, SDF realized that there is a wide gap of military technology between Japan and the United States forces, particularly with fast-developing US military transformation and Revolution in Military Affairs (RMA). Given the increasing possibility of Japan's sharing security burden and joint operation with US forces, SDF and Japanese Defense Agency (JDA) recognized the importance of developing space capability for narrowing the gap.

However, that was not the end of the story. The perception of Japanese people on security matters has dramatically changed by two events. First, the imminent threat of North Korea became visible when the Taepodong flew over Japanese territory in 1998. It was a big change of the policy paradigm. This incident put Japanese public as well as policy community in a panic mode. There was a strong demand to do something for avoiding North Korean to launch missiles towards Japan and protect our homeland. Thus, immediately after the Taepodong launch, the government made a decision to start a new satellite program, Information Gathering Satellite (IGS).

Nevertheless, it was seriously constrained by the existing legal interpretation. Although 
it was clear that the purpose of IGS was to monitor military activities of possible threats such as North Korea, but it was disguised as a "multi-purpose" (note: it was even difficult to mention "dual-use" because it implies the possibility of the participation of JDA) satellite, which also serves for civilian purpose.

However, because of the 1990 accord with the United States for satellite procurement, the IGS as a civilian non R\&D satellite should be placed under open procurement procedure. This has put Japanese government in a serious dilemma. If the government wants to develop IGS as multi-purpose satellite, the specification of satellite has to be open to public, but it cannot grant a defense satellite status (which is assumed to be exempted from 1990 Accord on satellite procurement) due to the Diet resolution.

The solution of this dilemma came from a careful legal interpretation. The government placed the control of the satellite not under JDA, but Cabinet Secretariat, a small office with national intelligence gathering mission and crisis management functions. So, the IGS was formally designed as a "crisis management satellite" with both civilian and military purposes ${ }^{8}$.

This incident provided a wide-ranging understanding among politicians that the legal constraints of "exclusively peaceful purpose" resolution was too strict to have a room for maneuver, and under the changing security environment in the post-Cold War period, it is non-sense to maintain such a rigid pacifist rules.

Furthermore, the development of Missile Defense (MD) program and Japanese Cabinet decision for participation to the program in 2003 raised another difficult question for Japanese space and security community. On the one hand, because of the "exclusively peaceful purpose" resolution, JDA and SDF would not be able to develop, launch and operate its own early warning or tracking satellite, which gathers crucial information about missile launch. Without its own early warning satellite, JDA has to depend on the early warning information from the United States. However, if JDA entirely depends on the US intelligence for initiating the deployment of MD counter-attack missiles, it would touch upon the sensitive issue of "collective defense". Japanese government took a unique interpretation of its Constitution Article 9 that Japan holds the right of collective defense, but it would not exercise it. So, if MD is set and ready for operation, but it would not be able to launch counter-attack missile unless the command comes from Japanese own early warning satellite. Thus, many people in Liberal Democratic Party (LDP), particularly those who are interested in defense issues, strongly demanded to reconsider the "exclusively peaceful purpose" clause of the Diet resolution in 1969.

\section{Kawamura's Initative}

\footnotetext{
8 Tsuyoshi Sunohara, Tanjo Kokusan Spai Eisei (The Birth of National Spy Satellite), Nikkei publishers, 2005.
} 
Although there has been an increasing demand for altering the interpretation of the "exclusively peaceful purpose" resolution, mounting financial pressure for administrative change and reducing space budget, there was no serious action taken by the government or politicians. However, the change started in early 2005 by Takeo Kawamura, a LDP politician who just left from the Minister of MEXT. During his ministership, he witnessed the failure of H-IIA no.6 launch carrying two IGS satellites. Although he was only responsible for the MEXT competence, which was the launch of H-IIA, the public as well as the government accused him for not supervising properly for nationally important satellite project, IGS. From his point of view, this was a huge twist of responsibility and competence. Even though JAXA was involved in the development of some technological aspects of IGS, he was clearly out of the loop and no position to take responsibility. In fact, there was no one who was directly in charge with IGS project because the main user, JDA, was supposed not to be involved in this program due to the Diet resolution. The Cabinet Secretariat, the nominal authority for IGS, was unable to take responsibility for its development and launch because of the shortage of manpower. Thus, neither JDA, Cabinet Secretariat, nor MEXT (and JAXA) was directly involved in this program. Kawamura thought that this was a critical failure of implementing national strategy, and something had to be done.

As soon as he stepped down from the Minister of MEXT, he formed a informal study group called "Consultation Group for National Strategy for Space (in short, it is called Kawamura Consultation Group)" with members of LDP working as Vice-Ministers in various ministries including MEXT, METI, JDA and Ministry of Foreign Affairs (MoFA). This Consultation Group intensively discussed the problems that Japanese space policy-making process including the amendment of the interpretation of "exclusively peaceful purpose" resolution and several public-private-partnership program such as Quasi-Zenith Satellite System (QZSS) and privatization of H-IIA ${ }^{9}$.

After 10 meetings of Kawamura Consultation Group, it produced a report in October $2005^{10}$. This 100 -some pages document argues that the source of problems on space policy-making is the lack of coherent strategy and institutional arrangement. Because of the historical background, Japanese space policy was dominated by the STA/MEXT and folded in the sphere of Science and Technology policy without strategic plan for using space assets for pursuing national strategic objectives, it argues. This particularity of Japanese space policy-making process has let Japanese space industry down and the presence of Japan in international stage small.

Thus, this report proposes to establish a law for defining new objectives for space activi-

\footnotetext{
${ }^{9}$ See Kazuto Suzuki, 'Adopting the European Model: Japanese Experience in Implementing Public-Private-Partnership in Space Program', Council for European Studies Fifteenth Biennial International Conference, The Drake (Chicago, Illinois), 31 March, 2006.

10 The report of the Consultation Group for National Strategy for Space: Towards a construction of new institutions for space development and utilization, October 2005.
} 
ties and institutional framework for structuring space policy-making process more coherent with three new settings. First, the report proposes that the government should create a ministerial post with a portfolio of space. This new ministerial post will be the center for strategic thinking and planning of space. The report underlines that the source of the problems of Japanese space policy is its concentration on developing new technology and lack of attention to the users' needs and demands, so it claims that the new minister for space shall make efforts to bring the user ministries in the process of policy-making for space, and aggregate the user needs which should be reflected to the R\&D program. Also the minister shall involve the defense and foreign policy authorities to use space assets for advancing Japanese space capability for security and foreign policy under current constitutional framework.

Second, the report also demands the government to establish a new forum of space user ministries. This forum, under the chairmanship of the new Minister for space, would be participated by the Ministers or Vice-Ministers of space user ministries including Ministries of Agriculture, Land and Transportation, Telecommunication etc. This idea came from the experience of the failure of QZSS, where four ministries, Ministry of Transportation (MLIT), of Telecommunications (MIC), METI and MEXT, were not able to make a compromise for sharing the financial burden for the program. Kawamura and the members of the Consultation Group were concerned the lack of coherent understanding among these ministries for supporting the program, and thought that the reason for this failure was because there was no dialogue among the ministries in the first place and no ministry wanted to take responsibility.

Third, this report suggests that the political community, including members of Consultation Group, should initiate the new discussion for the interpretation of the "exclusively peaceful purpose" resolution. Because this resolution was taken at the legislative body, the Diet, and it binds the action of the executive branch of the government. So, the decision to change the interpretation of the resolution should come from the Diet members. As discussed above, the political interest in space policy was not high for so many years, and there was no initiative from the Diet members for changing this resolution.

Furthermore, the report urged the government to take serious consideration for using space for achieving diplomatic objectives. Among the members of the Consultation Group, there was a strong concern about the development of Chinese space program. Of course, the members were impressed by the successful manned-space program, but their concern was not about the competition in the manned-space capability or space race for the Moon. Instead, their attention was paid to the recent development of Chinese action towards other Asian countries. In 2005, Chinese government concluded the signing of the establishing agreement for APSCO ${ }^{11}$ (Asia-Pacific Space Cooperation

\footnotetext{
11 "Asia-Pacific nations sign space convention", China Daily, October 27, 2005 (http://www.chinanews.cn//news/2005/2005-10-29/13271.html, Last seen 20 July, 2006).
} 
Organization) with Bangladesh, Indonesia, Iran, Mongolia, Pakistan, Peru and Thailand and Turkey $^{12}$. Although the Charter of APSCO has not entered into effect because it is currently under the ratification process, the presence of Chinese space in Asian region is remarkably high. They have already established AP-MCSTA (Asia-Pacific Multilateral Cooperation in Space Technology and Applications) ${ }^{13}$ with 13 member states. AP-MCSTA is an organization for developing small satellite technology and user-oriented applications. Both APSCO and AP-MCSTA are initiated by Chinese government, and they are attracting a lot of attention from developing countries. For many years, Japan was the leading country in this region and JAXA and MEXT was proud to initiate APRSAF (Asia-Pacific Regional Space Agency Forum) ${ }^{14}$ which coordinates the space program and enhance the cooperation among the space agencies in this region. However, this organization, as one might imagine, focused only technical aspects of space programs of different space agency, and there was no coordination of strategy or policy. There was a wide dissatisfaction from the members that Japan was not supporting the needs of developing countries, which was the transfer of technology and collaborative projects for space hardware, but JAXA could not appropriately respond to those demands. Thus, the Chinese initiatives attracted more attention.

In addition to the emerging Chinese role in Asian region, the members of Consultation Group paid close attention to the Chinese endeavor for using space as a diplomatic tool for bilateral relationship. Under a severe increase of oil price, China offered its satellite technology to Nigeria and Venezuela, both oil producing countries, for strengthening the bilateral relationship ${ }^{15}$. Since Japan as a huge oil importing country, the Chinese action towards these countries seems to be threatening for the secure supply of oil. The members of Consultation Group asked questions why Japan was not able to do the same thing before China did. They came to a conclusion that it was because Japanese space policy was so concentrated on the R\&D, and JAXA was not closely associated with MoFA. Particularly, Katsuyuki Kawai, then Vice-Minister for Foreign Affairs and the member of the Consultation Group, was furious about the response of the MoFA and JAXA to his demand for using satellite images to support Japan's contribution to the aftermath of Tsunami in Indonesia.

These frustrations of the Vice-Ministers in the Consultation Group encouraged the report to be more blunt and explicit to call for more political and strategic thinking to space policy. The members of Consultation Group realized that if Japanese government let JAXA to take responsibility

\footnotetext{
12 Turkey has recently signed the ASPCO Charter. See, "Turkey Signs Up For Asia-Pacific Space Program", Xinhua News Agency, 5 June, 2006.

${ }^{13}$ Even after the establishment of APSCO, this organization will continue to exist as a gateway for APSCO membership. For more information, see http://www.apmcsta.org/.

${ }^{14}$ For detail, see http://www.aprsaf.org/.

15 "China Prepares To Export First Satellite", Space Daily, July 3, 2005

(http://www.spacedaily.com/news/china-05zzzu.html, Last seen: 10 September, 2006); "China, Venezuela sign satellite launch agreement", China Daily, November 12, 2005

(http://news.xinhuanet.com/english/2005-11/02/content_3718959.htm, Last seen: 10 September, 2006)
} 
for international cooperation, it would lose the advantage of Japan being the leader in this region, and thus, they demanded the government to take serious consideration for coordinating Japanese foreign policy and APRSAF activities.

With these concerns in mind, the report of the Consultation Group was received well by the members of LDP and the government. The Kawamura's initiative paved the way for Japan to transform its space policy-making process.

\section{For Establishing the Basic Law}

Kawamura's ambition did not stop by publishing this report. He also brought this report to the Policy Research Council of LDP. As a ruling party, LDP's Policy Research Council has a strong leverage to change the government policy. It has the right to initiate policies and legislative actions, and without the consent of this Council, no legislative proposal would pass the Diet. Kawamura found that it would be appropriate to discuss his idea of reforming space policy-making in LDP, rather than bringing the issue to the government (as often in the case of Japanese policy-making process), because he needs the support of Diet members to re-interpret the "exclusively peaceful purpose" resolution. With support from Hidenao Nakagawa, then the Director of Policy Research Council and the No.3 of the LDP, Kawamura established "Special Committee on Space Development (SCSD)" and he became the leader of the Committee ${ }^{16}$.

With large number of Diet members, SCSD attracted a lot of media attention and gradually the participants of the meeting increased. By bringing space matter at LDP policy priority, many Diet members began to realize the importance of space activities in the national strategy and through media coverage, public too began to understand Kawamura's intention. In July 2006, the second North Korean missile launch campaign gave an extra boost to SCSD, because the public opinion dynamically shifted from guarding pacifist principles to more flexible interpretation of "exclusively peaceful purpose" clause.

Under these circumstances, SCSD of LDP decided to submit the "Basic Law on Space Activities" in next Diet session staring from September 2006 (though the submission of the draft law eventually postponed to January 2007 due to the lengthy negotiation with coalition partner, Komeito). The draft of Basic Law is already drafted and ready to be submitted. Let's look at some of the features of this new draft.

The first impression of this Basic Law is that it is a straight reflection of Kawamura Consultation Group report. It will set up new Minister for Space and Space Development Headquarters (a forum of user ministries with strong authority). The Minister for Space would be a "specially

\footnotetext{
${ }^{16}$ Formally, Shinya Ono is the Chairman of the Committee and Kawamura was only a Sub-chair for some reasons. Because Kawamura was already a Chairman of other committee (on Education), he was not able to chair two committees at once as party rule states. Thus, he was only a sub-chair, but Ono refrained from acting as a chairman in respect to Kawamura's initiative, so Kawamura was acting as de facto chairman.
} 
designated" minister who will not be in charge of the management of the ministry but to reside in the Cabinet Office for coordinating policies of different ministries. The Headquarters will be composed by all the ministers and some specially appointed members from academia and industry. Although this is an ambitious challenge, concerning the conservative attitude of the government towards any reform, there are hopes that these new institutions would provide positive force for more political attention and dynamics in space activities. However, one concern remains about the fiscal competency of this new Minister for Space. The Basic Law avoided to define who will draft the budget proposal and whether the Headquarters would have the power to formulate budget. Currently, the space budget is defined by the proposals from different ministries. The majority of the budget goes to MEXT/JAXA, some portion goes to Cabinet Secretariat for IGS, and the rest splits into different ministries for utilization of space assets. As long as this budgetary structure remains, it would be difficult for the Minister for Space and Headquarters to take initiatives for user-driven programs because the user ministries would be reluctant to spare their limited budget, and MEXT would refuse to reallocate its own budget. However, one member of SCSD suggested that the Headquarters would be the final decision-making body for the allocation of budget by bundling all budget request from various ministries and negotiate with the Ministry of Finance on behalf of those ministries ${ }^{17}$. This would give a significant leverage for the Headquarters because any budget request would have to go through the Headquarter, and ministries would lose their competence on defining space program without consent of the Headquarters and the Minister for Space.

The second point of the Basic Law is the question of security. As discussed above, the "exclusively peaceful purpose" resolution was under pressure in changing security environment around Japan in the post-Cold War period. Kawamura Consultation Group discussed this matter extensively, but did not give conclusive position on how to deal with the resolution. But in SCSD with a lot of members interested in security issues, many politicians fiercely insisted that the interpretation should be changed. Thus, the SCSD set up a sub-committee to discuss the possible scenario for changing the resolution and it came up with an idea to set out the security objective in the Basic Law. Obviously, Law is more binding than resolution. So, SCSD finally concluded that the one of the objectives of the Basic Law is "to promote the security of our homeland and people by contributing Japanese space capability to the international security arrangement". The SCSD, particularly Kawamura as an acting chairman of the Committee, strongly emphasized that this change of interpretation does not aim for aggressive use of space, i.e. enhancing Japanese military capability for invasion or using military forces to solve international disputes. Instead, this Basic Law confirms the principle of the Article 9 of the Constitution. The space assets will be used for crisis management and disaster monitoring in Asian region or peacekeeping missions in distant territories.

${ }^{17}$ Informal interview with the member of SCSD, under the condition of anonymity (December 22, 2006). 
It implies that Japan might have early warning satellite for MD which also falls into a category of self-defense. Thus, the Basic Law is designed to strengthen Japanese role in dispute settlement and crisis management with a peaceful means. It only tries to change the interpretation of the Diet resolution which prevented any use of space assets by military authority.

The third point of the Basic Law is about "industrialization" of space industry. Since 1990 when the Accord with the United States for satellite procurement entered into force, Japanese satellite industry lost its opportunity to improve international competitiveness through government programs. During the period of commercialization in the late-1990s, Japanese industry was not able to enter into the booming market (in retrospect, it might have limited the damage from the downturn of the market though). Nevertheless, long history of concentrating on R\&D and technological development has made Japanese industry entirely relying on the government R\&D funding, which was decreasing due to the fiscal constraints. Furthermore, because of the nature of government-funded R\&D projects, Japanese industry was not concentrated on improving international competitiveness, i.e. improving reliability, reducing costs and meeting with deadlines. If Japanese industry continues to depend on government procurement, Japanese industrial and technological capability will inevitably face the cul-de-sac. The weakening of Japanese industrial base would undermine its capacity to develop space system for security purposes. Thus, the Basic Law urged the government as well as the industry to steer up its effort of "industrialization", i.e. strengthening industrial capability and autonomous business foundation from public budget. In order to achieve this objective, the Basic Law argues to set up a policy of "anchor tenancy", which borrows the idea of Public-Private-Partnership (PPP) exercised in Europe. Particularly, the experience of Private Finance Initiative (PFI) scheme of SKYNET 5, British military communication satellite, was considered as an ideal model. The PFI scheme would be able to avoid infringement with 1990 Accord since it is not a pure "public procurement" as such. The procuring body is not the government agency but private enterprise, and the government only plays the role of principal customer. The private enterprise would have stable income from government user fee, but it would endeavor market opportunity if the satellite is not used by the government. In fact, this scheme was employed in the case of QZSS ${ }^{18}$, but as discussed above, it was unsuccessful because of the turmoil in the government. So the SCSD believed that if the Minister for Space takes the initiative and the Headquarters functions properly, the government can offer stable "anchor tenancy" to the private enterprise, and the "industrialization" would be successful.

Although the Basic Law focuses extensively on the user-side of space projects, it does not neglect the importance of R\&D. However, its interest in R\&D is not based on the concept of technological "catch-up", but on the originality and national prestige. The experience of "Hayabusa"

${ }^{18}$ See Suzuki, 'Adopting the European Model', op. cit. 
was a good example of the new concept of R\&D. For many years, Japanese space R\&D focused to domestically reproduce the technology available elsewhere. But the Basic Law demands that the copying of someone's technology is not the way to improve industrial competitiveness or strategic importance of space. Instead, it argues that developing original plan and technology which would fascinate the public and international space community would serve better for Japan.

\section{Conclusion}

After analyzing the objectives and aims of the Basic Law, the obvious questions should be asked: Is this really possible? Does anyone, particularly those who benefited from the old regime, object to this proposal? Would user ministries happily cooperate with the new Minister for Space, particularly Japanese Defense Agency which developed a habit of not using space? Does industry change from comfortable dependence on the government budget to taking business risks?

Of course, changing normative foundation of policy-making is not easy. It is always a political struggle. MEXT and JAXA might be the strongest opposition since they might lose the monopoly situation of space policy-making. In response to these changes, JAXA began to shift its policy focus from R\&D to more user-oriented programs in satellite programs for providing impression that it is adopting the new policy objectives, but at the same time, JAXA strongly claims that Japan is still behind other countries and "catching up" is needed. On the other hand, JDA, which became the Ministry of Defense in January 2007, set up a new "Strategy Planning Office" which includes space as one of the pillar of strategic policy ${ }^{19}$. Industry might be reluctant to be autonomous from the government budget, but it realized that the government expenditure is in decline with or without Basic Law.

If Japanese space policy-making process continues as it is today, the space community would be in jeopardy. Although Japanese economy is in recovery, space budget would unlikely increase under any circumstance because the huge government deficit and debt would not be resolved in foreseeable future. International competitiveness of space industry needs to be improved in order to sustain sufficient level of technological and industrial base. And most of all, the "exclusively peaceful purpose" resolution should be redefined in uncertain security condition around Japan. The world has changed from Cold War structure, and it is the time for Japan to transform its space policy.

\footnotetext{
${ }^{19}$ While JDA was an agency, the strategic decision making was in the hands of Prime Minister and Cabinet Secretary. But because of the change of status to Ministry, it became autonomously responsible for strategic planning.
} 